\title{
Knowledge, Perceptions, and Preferred Information Sources Related to COVID-19 Among Central Pennsylvania Adults Early in the Pandemic: A Mixed Methods Cross-Sectional Survey
}

\author{
Lauren Jodi Van Scoy, MD ${ }^{1,2,3,4}$ \\ Erin L. Miller ${ }^{5}$ \\ Bethany Snyder, MPH ${ }^{1,4}$ \\ Emily Wasserman, MAS ${ }^{3,4}$ \\ Vernon M. Chinchilli, $\mathrm{PbD}^{3}$ \\ Aleksandra E. Zgierska, $M D, P b D^{3,5,8}$ \\ David Rabago, $M D^{3,5}$ \\ Courtney L. Lennon, $M D^{5}$ \\ Daniella Lipnick, $M S^{6}$ \\ Olubukola Toyobo ${ }^{6}$ \\ Mack T. Ruffin IV, MD, MPH \\ Robert P. Lennon, MD, JD

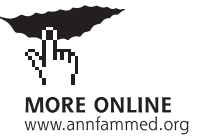

Conflicts of interest: authors report none.

\section{CORRESPONDING AUTHOR}

Robert P. Lennon

Associate Professor of Family and Community Medicine

Penn State College of Medicine

500 University Dr

Hershey, PA 17033-0850

rlennon@pennstatehealth.psu.edu

\begin{abstract}
PURPOSE To explore public knowledge, understanding of public health recommendations, perceptions, and trust in information sources related to COVID-19.

METHODS A cross-sectional survey of central Pennsylvanian adults evaluated self-reported knowledge, and a convergent, mixed methods design was used to assess beliefs about recommendations, intended behaviors, perceptions, and concerns related to infectious disease risk, and trust of information sources.

RESULTS The survey was completed by 5,948 adults. The estimated probability of correct response for the basic knowledge score, weighted with confidence, was $0.79(95 \% \mathrm{Cl}, 0.79-0.80)$. Knowledge was significantly higher in patients with higher education and nonminority race. While the majority of respondents reported that they believed following CDC recommendations would decrease the spread of COVID-19 in their community and intended to adhere to them, only $65.2 \%$ rated social isolation with the highest level of belief and adherence. The most trusted information source was federal public health websites (42.8\%). Qualitative responses aligned with quantitative data and described concerns about illness, epidemiologic issues, economic and societal disruptions, and distrust of the executive branch's messaging. The survey was limited by a lack of minority representation, potential selection bias, and evolving COVID-19 information that may impact generalizability and interpretability.
\end{abstract}

CONCLUSIONS Knowledge about COVID-19 and intended adherence to behavioral recommendations were high. There was substantial distrust of the executive branch of the federal government, however, and concern about mixed messaging and information overload. These findings highlight the importance of consistent messaging from trusted sources that reaches diverse groups.

Ann Fam Med 2021;19:293-301. https://doi.org/10.1370/afm.2674.

Annals "Online First" article.

\section{INTRODUCTION}

$\mathrm{E}$ ffective communication is critical for successful pandemic management. ${ }^{1-6}$ Ineffective messaging may result in failure of the public to comply with precautionary measures, propagation of fears and misconceptions, preventable overuse of health services, ${ }^{7,8}$ and inappropriate or inadequate policy decisions. ${ }^{9}$ Ineffective communication in the early stages of the current coronavirus disease 2019 (COVID-19) pandemic likely contributed to its rapid spread and high mortality ${ }_{1}^{10}$ particularly in racial and ethnic minority groups. ${ }^{11}$ As patients turn to their primary care physicians for guidance and information about the pandemic, it is imperative that clinicians understand the perceptions, understanding, and health beliefs that play a key role in patients' behavior, and the information sources used, so clinicians may better bridge key knowledge gaps. 
A national telephone survey $(\mathrm{n}=1,216)$ found a mixed understanding of COVID-19 recommendations. ${ }^{12} \mathrm{~A}$ telephone survey conducted in Chicago $(\mathrm{n}=630)$ found lower COVID-19 knowledge among participants who were older, Black, unmarried, unemployed, retired, had poorer health, or had lower health literacy. ${ }^{12}$ This paucity of data identifies a critical gap in knowledge. The objective of this study is to address this gap to help clinicians provide better messaging to their patients, and leaders better disseminate evolving mitigation strategies.

\section{METHODS}

This cross-sectional online survey study was conducted from March 25-31, 2020, using a convergent mixed methods approach ${ }^{13}$ to explore public knowledge constructs related to COVID-19.

\section{Survey Design}

Because no validated questionnaires about COVID-19 existed, we adapted the European Standard Questionnaire on Risk Perception of an Infectious Disease Outbreak. ${ }^{14}$ Knowledge questions were based on information published on the US Centers for Disease Control and Prevention (CDC) website. ${ }^{15}$ The questionnaire was refined based on feedback from 13 individuals, using 2 rounds of cognitive interviewing procedures that utilized the think-aloud technique. ${ }^{16,17}$ The survey was further refined through pilot testing with a random sample of 1,000 potential participants to ensure adequate knowledge discrimination and qualitative sensibility.

The final survey included 65 to 92 items, depending upon branching logic, and assessed 4 constructs: (1) knowledge and corresponding confidence in that knowledge (15 items each; 30 total) $)_{i}(2)$ beliefs about and intention to follow CDC recommendations (10 items) $)_{i}$ (3) perceptions and concerns about COVID-19 and other infections (15 items); and (4) information sources ( 7 items). There were also 18 demographic questions, which included race and ethnicity categories and terms used by the US Census Bureau. During analysis, 8 of the 15 knowledge items were identified as a basic knowledge set (ie, not testing nuanced medical information).

Following the convergent mixed methods design, we developed 3 open-ended questions to qualitatively assess 3 of the 4 constructs (excluding knowledge): (1) "Please explain what, if anything, prevents you personally from following CDC recommendations about COVID-19"; (2) "What worries you most about the COVID-19 pandemic?"; and (3) "How do you feel about the way information regarding COVID-19 has been delivered to you?" The fourth qualitative question broadly captured additional thoughts participants wanted to contribute: "Is there anything else you would like to share regarding the COVID-19 pandemic?"

\section{Sample}

The questionnaire was sent to a convenience sample of adults enrolled in a central Pennsylvanian health care system, the database of which contains 121,573 unique, valid e-mail addresses. This sampling area consisted of primarily Caucasian and rural or suburban residents, some living in smaller urban areas. Potential participants received an e-mail from Penn State Health marketing inviting them to anonymously complete the survey through a link to an online electronic data capture tool, REDCap (Vanderbilt University) ${ }^{17} ; 1$ reminder was sent 48 hours after the initial invitation e-mail.

\section{Institutional Review Board Approval and Reporting Guidelines}

The Pennsylvania State University College of Medicine Institutional Review Board approved the study protocol. This study adhered to the Strengthening the Reporting of Observational Studies in Epidemiology (STROBE) and the Consolidated Criteria for Reporting Qualitative Research (COREQ) guidelines.

\section{Statistical Analysis}

Each true/false knowledge item was scored as correct or incorrect. Each knowledge item had a corresponding 5 -point confidence score ( 1 = Extremely confident, $5=$ Not at all confident [just guessing]). When a knowledge item was completed but the corresponding confidence score was missing, simple imputation was performed by constructing 2-way frequency tables based on both completed knowledge and corresponding completed confidence scores for each item, and imputing with the mode of the confidence score determined from each complete set for each corresponding knowledge item.

The 15 binary knowledge measures were analyzed via a generalized linear mixed-effects model (GLMM) with a logistic link function and a random effect for the participant, modeling the probability of a correct response. Weighted and unweighted analyses were performed $d_{i}$ the latter including a weighting variable equal to the inverse of the confidence score. Subgroup comparison analyses for select demographic measures were assessed. The logarithm of the estimated odds ratios from the GLMM were transformed to probability estimates, with 95\% CIs. The false-discovery rate was applied to report adjusted $P$ values for statistical comparisons.

To quantify the relationship between perceptions regarding the likelihood and concern for various 
infectious disease diagnoses, and between the recommendation efficacy beliefs and intended adherence to those recommendations, we first descriptively summarized these data using $5 \times 5$ frequency tables. A GLMM, with a cumulative logistic link function and a random effect for the participant, was used to perform a bivariate analysis between likelihood of contraction and efficacy belief with concern of diagnosis and intention to follow the recommendation, respectively. Probability estimates and their 95\% CIs were calculated, along with the intraclass correlation (ICC) and corresponding 95\% CI. When combinations of responses were sparse or skewed, collapsed category responses were explored to analyze the bivariate relationship with symmetry. Even after collapsing, the ICC was still occasionally not reportable due to instability. SAS Version 9.4 (SAS Institute Inc) was used for all statistical analysis.

\section{Qualitative Analysis}

Stratified purposive sampling ${ }^{18}$ was used to select 250 qualitative responses with equal representation from each of the following strata: race (nonminority vs minority), education level (lower vs higher), and sex (male vs female). Conventional content analysis was used to analyze survey responses using NVivo 12 (QSR International). ${ }^{19}$ Two analysts reviewed the 250 -participant surveys to generate a preliminary codebook representing categories and codes that emerged. Data saturation was achieved within approximately the first 50 responses. Codes within each category were then defined and iteratively discussed.

Four analysts coded an additional 20 responses using the constant comparison method. ${ }^{20}$ The codebook was refined through group discussion. The refined codebook was used by 2 analysts to analyze an additional 40 responses each. A third analyst adjudicated differences in codes. Upon reaching inter-rater reliability of 0.65 , the remainder of the responses were coded. All 250 records were coded by 2 coders.

\section{Mixed Methods Integration}

Qualitative themes were merged and aligned with conclusions from the quantitative data. Themes are presented in a joint display for each quantitative construct. ${ }^{21}$

\section{RESULTS}

\section{Participation}

The e-mail was opened by 53,585 of those who received it (44.1\%). Of those who opened the e-mail, 11,675 opened the link $(21.8 \%) ; 8,072$ participants completed portions of the survey (69.1\%). Analysis was conducted on the 5,948 consenting respondents who answered at least 1 knowledge and 1 risk-stratification question $(73.7 \%$ of all who opened the survey, $50.9 \%$ of those who opened the survey link, $11.1 \%$ of those who opened the e-mail, and $4.8 \%$ of the entire list).

\section{Knowledge}

Respondents were predominantly female, Caucasian, with nonmedical professions (Table 1). Knowledge results are reported in Table 2 . The estimated probability of correct response for the 8-item basic knowledge score, weighted with confidence, was 0.79 (95\% CI, $0.79-0.80)$ and for the full 15 -item knowledge assessment, 0.75 (95\% CI, 0.74-0.75). The knowledge item that yielded the lowest estimated probability of a correct response pertained to available nonprescription treatments for COVID-19 (Table 2). Respondents with a Bachelor's degree or higher had 1.64 times higher odds of responding correctly to the 8 basic knowledge items than those without a Bachelor's degree $(95 \% \mathrm{CI}$, 1.55-1.73; (Supplemental Table 1, available at https:// www.AnnFamMed.org/lookup/suppl/doi:10.1370/afm. 2674///DC1). There were no differences in knowledge based on age or sex (Supplemental Table 2, Supplemental Table 3, and Supplemental Table 4, available at https://www.AnnFamMed.org/lookup/suppl/ doi:10.1370/afm.2674/-/DC1).

\section{Beliefs About CDC Recommendations and Intended Behavior}

The majority of respondents believed that social isolation would "most certainly" decrease the spread of COVID-19 in their community and reported that they intended to adhere to this recommendation $(65.2 \%$; Table 3). The ICC for the relationship between belief about social isolation effectiveness and the intent to follow this recommendation was moderate $(0.68,95 \%$ CI, 0.65-0.71). Analysis of other recommended behaviors are reported in Supplemental Table 5 (https:// www.AnnFamMed.org/lookup/suppl/doi:10.1370/ afm.2674/-/DC1).

Responses to the question, "What, if anything, prevents you personally from following CDC recommendations about COVID-19?" revealed 2 major themes (Table 3). While most participants reported no or minimal barriers to following CDC recommendations (Theme 1), participants that reported barriers gave reasons of essential life or medical needs (Theme 2).

\section{Perceptions and Concerns Related to COVID-19 and Influenza Risk}

Most respondents (93.5\%) expressed concern ("slightly concerned," "concerned," or "very concerned") about being diagnosed with COVID-19 compared with $70.0 \%$ regarding influenza diagnosis in the next year. Further, $75.6 \%$ of respondents felt 
Table 1. Participant Demographics $(n=5,948)$

No. (\%)

No. (\%)

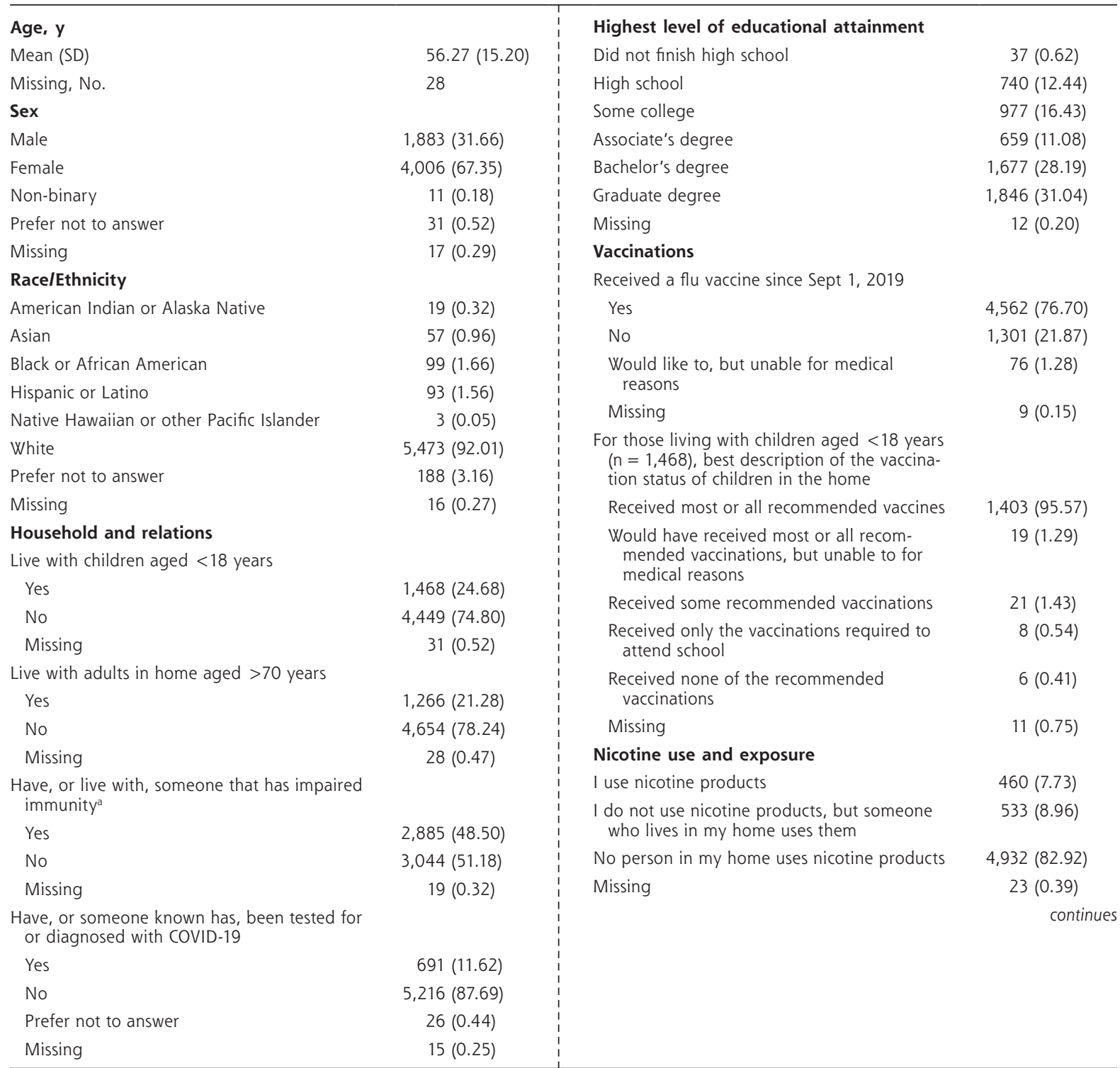

Note: Categorical measures are reported as frequency (percent). Continuous measures are summarized as mean (SD).

a For example, chronic lung disease, renal disease, chronic hypertension, diabetes, or active cancer.

it was "possible," "likely," or "very likely" that they would be diagnosed with COVID-19 in the next year, compared with $64.7 \%$ when asked about their likelihood of being diagnosed with influenza. This descriptive contrast may be influenced by whether respondents received vaccinations or have knowledge of vaccination efficacy, which our survey did not address. The ICC for the relationship between the perceived likelihood of COVID-19 infection and concern about being diagnosed with COVID-19 was 0.19 (95\% CI, 0.16-0.22i (Supplemental Table 6, https://
www.AnnFamMed.org/lookup/suppl/doi:10.1370/ afm.2674/-/DC1)) and 0.11 (95\% CI, 0.07-0.15) for the flu, indicating weak relationships (Supplemental Table 7, https://www.AnnFamMed.org/lookup/suppl/ doi:10.1370/afm.2674/-/DC1).

Three themes emerged in response to the question, "What worries you the most about the COVID-19 pandemic?" (Supplemental Table 6). First, respondents most commonly indicated that their worries were related to contracting COVID-19 themselves or that at-risk family members would "get it" (Theme 3). 
Table 1. Participant Demographics $(n=5,948)$ continued

No. (\%)

No. (\%)

\section{Employment}

Best description of current employment status

Full-time employment (Employed)

Part-time employment (Employed)

Not employed, seeking employment

Not employed, not seeking employment

Not employed, full-time student

I Primary language spoken in the home

English

Spanish

$5,858(98.49)$

$2,384(40.08)$

600 (10.09)

78 (1.31)

362 (6.09)

$73(1.23)$

Retired

Prefer not to answer

$2,288(38.47)$

$150(2.52)$

$13(0.22)$

Missing

For those employed ( $n=2,984)$, best descrip-

tion of work status related to COVID-19

I have missed work, but will still be paid

I have missed work, and will not be paid for

I have not missed work

$1,876(62.87)$

Unsure

Missing

$11(0.37)$

For those employed ( $n=2,984)$, best description of work location related to COVID-19

I still go to my regular place of work

I now work remotely for part of my time

I now work remotely for most or all of my time

$1,442(48.32)$

Unsure

342 (11.46)

Missing

For those employed ( $n=2,984)$, how many

days of work did you miss in calendar year 2019?

Mean (SD)

Missing, N

For those employed ( $n=2,984)$, how many days of work do you think you will miss in calendar year 2020, including days missed between the beginning of the year and now?

Do you work in the medical profession?

\section{Diagnoses and conditions}

Ever diagnosed with heart disease

Ever diagnosed with diabetes

$$
\text { Yes }
$$

Ever diagnosed with lung disease

Immunosuppression

COVID-19 risk stratab

Low

Note: Categorical measures are reported as frequency (percent). Continuous measures are summarized as mean (SD).

a For example, chronic lung disease, renal disease, chronic hypertension, diabetes, or active cancer.

${ }^{b}$ High risk defined as age $\geq 60$ years or any "Yes" response to any of the 4 diagnoses and/or conditions (heart disease, diabetes, lung disease, or immunocompromised). To be classified as high risk, the union of any of these definition components could be missing responses as long as at least one of the specified criteria were met. Low risk defined as age $<60$ years and responded "No" to all 4 diagnoses and conditions (heart disease, diabetes, lung disease, and immunocompromised). To be classified as low risk, all definition components must be nonmissing with all responses meeting the intersection of all low-risk criteria.

Participants often described concerns about delayed testing impacting abilities to effectively manage the virus, but not about severity of illness. Second, respondents noted concerns related to public health issues (Theme 4), in particular about asymptomatic spread of the virus and community members not practicing social distancing. Third, respondents had anxieties related to economic impact and societal disruptions, ranging from "the economy in general" to the impact of layoffs on workers and small businesses (Theme 5).

\section{Information Sources and Trust}

The single most trusted source by respondents for health information was government websites (ie, CDC, National Institutes of Health $[\mathrm{NIH}]$, and the World Health Organization [WHO]) (42.8\%), followed by television news (27.2\%). Three themes emerged related to information sources and trust (Supplemental Table 8, https://www.AnnFamMed.org/lookup/suppl/ doi:10.1370/afm.2674///DC1). Respondents reported distrust of information provided by the executive 
Table 2. Knowledge Assessment Summary, Unweighted and Weighted by Confidence in Response $(n=5,948)$

\begin{tabular}{|c|c|c|c|c|}
\hline Question & Correct $^{\mathrm{a}}$ & $\begin{array}{l}\text { Missing Knowledge } \\
\text { Response and } \\
\text { Confidence } \\
\text { Weight }(\mathrm{N})^{\mathrm{b}}\end{array}$ & $\begin{array}{l}\text { Unweightedc } \\
\text { Item Level }\end{array}$ & $\begin{array}{l}\text { Weighted } \\
\text { Item Level }\end{array}$ \\
\hline $\begin{array}{l}\text { Treatments for the symptoms of COVID-19 are available } \\
\text { without a prescription. }{ }^{\text {e }}\end{array}$ & $\mathrm{T}$ & 19 & $0.44(0.43,0.45)$ & $0.41(0.40,0.43)$ \\
\hline $\begin{array}{l}\text { Most hospitalized patients with COVID-19 should be treated } \\
\text { in an ICU.e }\end{array}$ & $\mathrm{F}$ & 25 & $0.64(0.62,0.65)$ & $0.65(0.63,0.66)$ \\
\hline $\begin{array}{l}\text { The CDC recommends using corticosteroids for COVID-19 } \\
\text { patients with acute respiratory distress syndrome (ARDS). }\end{array}$ & $\mathrm{F}$ & 176 & $0.56(0.54,0.57)$ & $0.57(0.55,0.60)$ \\
\hline COVID-19 is the first coronavirus to cause disease in humans. & $\mathrm{F}$ & 27 & $0.92(0.91,0.92)$ & $0.95(0.94,0.95)$ \\
\hline $\begin{array}{l}\text { Patients with shortness of breath, fever, and cough should } \\
\text { call the emergency department before arrival. }{ }^{\text {e }}\end{array}$ & $\mathrm{T}$ & 21 & $0.87(0.86,0.88)$ & $0.89(0.88,0.90)$ \\
\hline $\begin{array}{l}\text { Patients whose first (early) symptoms are severe are more } \\
\text { likely to die from COVID-19 than those whose first (early) } \\
\text { symptoms are less severe. }\end{array}$ & $\mathrm{F}$ & 47 & $0.75(0.74,0.76)$ & $0.77(0.75,0.79)$ \\
\hline $\begin{array}{l}\text { Children ages } 5 \text { and under are at higher risk of death from } \\
\text { COVID-19.e }\end{array}$ & $\mathrm{F}$ & 33 & $0.85(0.84,0.86)$ & $0.88(0.87,0.89)$ \\
\hline $\begin{array}{l}\text { In someone who has not received the measles vaccine, } \\
\text { measles is more contagious than COVID-19. }\end{array}$ & $\mathrm{T}$ & 62 & $0.40(0.39,0.41)$ & $0.43(0.41,0.45)$ \\
\hline $\begin{array}{l}\text { The incubation period for the coronavirus that causes } \\
\text { COVID-19 is up to } 21 \text { days. }\end{array}$ & $\mathrm{F}$ & 39 & $0.48(0.47,0.49)$ & $0.47(0.46,0.49)$ \\
\hline $\begin{array}{l}\text { Healthy people should wear facemasks to help prevent the } \\
\text { spread of COVID-19. }\end{array}$ & $\mathrm{F}$ & 20 & $0.83(0.82,0.84)$ & $0.85(0.84,0.86)$ \\
\hline $\begin{array}{l}\text { A vaccine for COVID-19 should be available within approxi- } \\
\text { mately } 3 \text { months. }\end{array}$ & $\mathrm{F}$ & 26 & $0.87(0.86,0.88)$ & $0.91(0.90,0.92)$ \\
\hline $\begin{array}{l}\text { CDC recommends the use of alcohol-based hand sanitizers } \\
\text { with greater than } 60 \% \text { ethanol or } 70 \% \text { isopropanol. }\end{array}$ & $\mathrm{T}$ & 34 & $0.91(0.91,0.92)$ & $0.93(0.92,0.94)$ \\
\hline $\begin{array}{l}\text { Currently, the CDC recommends that everyone with COVID- } \\
19 \text { symptoms should get tested. }\end{array}$ & $\mathrm{F}$ & 28 & $0.51(0.49,0.52)$ & $0.53(0.51,0.54)$ \\
\hline $\begin{array}{l}\text { COVID-19 testing is not recommended for individuals with } \\
\text { no symptoms, even if they were exposed to someone with } \\
\text { confirmed COVID-19 within the past } 2 \text { weeks. }{ }^{e}\end{array}$ & $\mathrm{~T}$ & 20 & $0.68(0.67,0.69)$ & $0.71(0.69,0.73)$ \\
\hline Total Score (15-Item) & & 616 & $0.71(0.70,0.71)$ & $0.75(0.74,0.75)$ \\
\hline Total Score (8-Item) & & 616 & $0.76(0.76,0.76)$ & $0.79(0.79,0.80)$ \\
\hline
\end{tabular}

$C D C=$ Centers for Disease Prevention and Control; $I C U=$ intensive care unit; $F=$ false; $T=$ true.

${ }^{a}$ Correct response according to information publicly available from the Centers for Disease Prevention and Control website as of the date the survey was distributed (03/25/2020).

b Simple imputation was used for confidence items where respondents answered the knowledge component, but skipped the corresponding confidence component ( $n=170$ imputed confidence level values). After imputing confidence levels, any item missing a knowledge response was also missing a confidence level, and vice versa. c The statistical model used to calculate unweighted predicted probabilities of correct responses (and corresponding $95 \%$ confidence limits) excluded $n=616$ missing knowledge response questions. Note that $n=616$ reflects the number of response items, not the number of patient respondents. All $n=5,948$ patient respondents were included in the analysis.

${ }^{d}$ The statistical model used to calculate weighted predicted probabilities of correct responses (and corresponding $95 \%$ confidence limits) while accounting for the corresponding confidence in the response excluded $n=616$ missing knowledge response questions and $n=616$ missing weight values. Note that $n=616$ reflects the number of items, not the number of patient respondents. All $n=5,948$ patient respondents were included in the analysis.

e Item belongs to selected 8-item subset.

branch of the federal government (Theme 6). They describe concerns about politicizing the response to the pandemic and negative feelings about COVID-19's media coverage (Theme 7). Respondents felt overwhelmed by "information overload," frustrated by mixed messaging, and concerned about misinformation. To counter this, participants described a need to "filter" information from multiple sources. When asked about what information was viewed as insufficient, respondents commonly described questions about symptom management (ie, over-the-counter treatment of symptoms), diagnostic testing, viral behavior, and immunity (ie, how long are patients contagious; Theme 8).

\section{DISCUSSION}

In this convergent, mixed methods, cross-sectional survey of 5,948 adults from a health system in central Pennsylvania, most respondents had high COVID-19 
Table 3. Beliefs Regarding Efficacy of, and Willingness to Follow, CDC Recommendations

\begin{tabular}{|c|c|c|c|c|c|c|c|c|}
\hline \multirow{2}{*}{$\begin{array}{l}n=5,943 \\
\mathrm{ICC}(95 \% \mathrm{Cl}) \\
0.68(0.65,0.71)\end{array}$} & & \multicolumn{7}{|c|}{$\begin{array}{l}\text { Social Isolation Belief vs Follow } \\
\text { Will You Follow Social Isolation, Even if You Have } \\
\text { No Symptoms (Avoiding Large Crowds)? }\end{array}$} \\
\hline & & Missing & $\begin{array}{l}\text { Certainly } \\
\text { Not }\end{array}$ & $\begin{array}{l}\text { Probably } \\
\text { Not }\end{array}$ & Maybe & $\begin{array}{l}\text { Probably } \\
\text { Yes }\end{array}$ & $\begin{array}{l}\text { Most } \\
\text { Certainly }\end{array}$ & Total \\
\hline \multirow{7}{*}{$\begin{array}{l}\text { Do you think that } \\
\text { social isolation, } \\
\text { even if you have no } \\
\text { symptoms (avoiding } \\
\text { large crowds), will } \\
\text { decrease the spread } \\
\text { of COVID-19 in your } \\
\text { community? }\end{array}$} & Missing & $5(0.1)$ & $1(0.0)$ & $1(0.0)$ & $0(0.0)$ & $8(0.1)$ & $58(1.0)$ & $73(1.2)$ \\
\hline & Certainly not & $0(0.0)$ & $7(0.1)$ & $3(0.1)$ & $2(0.0)$ & $2(0.0)$ & $4(0.1)$ & $18(0.3)$ \\
\hline & Probably not & $0(0.0)$ & $8(0.1)$ & $12(0.2)$ & $21(0.4)$ & $15(0.3)$ & $9(0.2)$ & $65(1.1)$ \\
\hline & Maybe & $4(0.1)$ & $7(0.1)$ & $18(0.3)$ & $54(0.9)$ & $121(2.0)$ & $83(1.4)$ & $287(4.8)$ \\
\hline & Probably yes & $11(0.2)$ & $6(0.1)$ & $4(0.1)$ & $45(0.8)$ & $478(8.0)$ & $773(13.0)$ & $1,317(22.1)$ \\
\hline & Most certainly & $35(0.6)$ & $10(0.2)$ & $7(0.1)$ & $21(0.4)$ & $238(4.0)$ & $3,877(65.2)$ & $4,188(70.4)$ \\
\hline & Total & $55(0.9)$ & $39(0.7)$ & $45(0.8)$ & $143(2.4)$ & $862(14.5)$ & $4,804(80.8)$ & 5,948 \\
\hline \multicolumn{9}{|c|}{ Related Qualitative Themes \& Quotes } \\
\hline \multicolumn{9}{|c|}{$\begin{array}{l}\text { Theme 1. There are minimal or no barriers to following CDC recommendations. } \\
\text { "There is nothing that prevents me from following CDC recommendations." }\end{array}$} \\
\hline \multicolumn{9}{|c|}{$\begin{array}{l}\text { Theme 2. Life or medical obligations require occasional disregard for CDC recommendations. } \\
\text { "I must work to provide for my family." }\end{array}$} \\
\hline \multicolumn{9}{|c|}{$\begin{array}{l}\text { "I have a family of } 5 \text { and unfortunately do need to go to the grocery store at least once a week because I can't keep more than a week's worth } \\
\text { of food stored properly at my house." }\end{array}$} \\
\hline \multicolumn{9}{|c|}{ "The only time I have left my house is for OBGYN appointments." } \\
\hline \multicolumn{9}{|c|}{ "I'm not socially isolating because I'm also concerned about the long-term mental health effects of loneliness." } \\
\hline
\end{tabular}

-related knowledge, similar to that reported in an earlier smaller-scale survey. ${ }^{22}$ These scores suggest that COVID-19 messaging has been generally effective within these populations. Knowledge disparity based on education, however, suggests that messaging to groups with lower education levels needs improvement. Differences in knowledge scores across racial categories were observed, but should be interpreted with caution because much like the geographic region from which this survey was obtained, White, non-Hispanic persons were overrepresented in this survey.

The majority of respondents believe in the effectiveness of current CDC recommendations as a means to prevent the spread of COVID-19 and intend to follow these recommendations. Qualitative data supported the notion that participants' health beliefs about CDC recommendations supported their intention to follow them. This is reassuring because while knowledge plays an important role in behavior, health beliefs and perceptions affect how individuals receive and respond to information they receive.

In bivariate analysis, only a weak relationship between perceived likelihood of diagnosis with COVID-19 and concern for such a diagnosis was noted, suggesting that participants may be more concerned about the potential harm from being diagnosed with COVID-19, and less about their likelihood of infection. Although individuals cannot control the severity of illness should they contract COVID-19, they can reduce infection risk through preventive measures. Thus, messaging that balances illness severity with prevention efficacy may reduce fear and anxiety related to the disease. The integration of qualitative responses with this data did not entirely support this interpretation, as respondents did not commonly describe specifics about medical concerns, but articulated their concerns more broadly as worry about "getting it" or just becoming ill in general. Additional evaluation to better understand public anxieties about the medical aspects of COVID-19 is warranted.

Most participants $(72.5 \%)$ felt that it was at least "possible" that they would be diagnosed with COVID-19 over the next year and were at least "slightly concerned" about this, while only $47.0 \%$ felt this for influenza, an infection that was frequently compared with COVID-19 in Pennsylvania media. A similar discrepancy was observed in a smaller study that found $87.1 \%$ of respondents were worried about COVID-19 yet only $64.1 \%$ of were worried about getting influenza. ${ }^{22}$ The lack of a COVID-19 vaccine at the time of the study may have contributed to the higher risk perception. 
Government websites (ie, CDC) were the most frequently cited $(42.8 \%)$ "single most trusted source" for COVID-19-related information at the time of this study. Qualitatively, participants desired basic, readily available information (eg, how to treat common symptoms of COVID-19 using over-the-counter medications). The qualitative data indicated substantial distrust in the executive branch of the government, but not health agencies like the CDC. Detailed analysis of this distrust goes beyond the scope of this article and will be reported separately; however, at minimum it suggests that information dissemination may be best received by health agencies like the $\mathrm{CDC}$ vs the executive branch. Leveraging mobile health technologies may help facilitate real-time information disclosures ${ }^{23}$ noting that rural or underserved areas with less access to information via technology who have an increased risk of poor outcomes ${ }^{24,25}$ may require different outreach strategies.

We identified racial disparities in COVID-19 knowledge, as have others, ${ }^{22}$ which, combined with racial health disparities in COVID-19 outcomes, ${ }^{24,25}$ warrant larger studies with greater demographic diversity to investigate inequities with messaging. Broad generalizability of our study is limited by lack of racial diversity, minimal urban representation, and because the study region area had not yet directly experienced significant impacts of COVID-19 at the time of the survey. Further, the survey has not been validated. Selection bias may contribute to the relatively high knowledge scores, as those who chose to respond to the survey may be more attentive to COVID-19-related issues. Finally, the rapidly changing knowledge stream about COVID-19 may impact the generalizability of findings.

Our study has several strengths. To our knowledge, at the time of this study, this was the largest and first mixed methods assessment of the COVID-19 pandemic. Our convergent mixed methods design offers a deeper understanding and context to the quantitative analysis. A rigorous data integration in accordance with best practices in mixed methods was performed, strengthening the credibility and validity of our findings. ${ }^{13}$

In conclusion, this study suggests that knowledge about COVID-19 and adherence to behavioral recommendations are generally high. Lower education groups and minorities appear to be at risk from lesser knowledge, although further exploration is needed. We were surprised to find only a weak relationship between the degree of likelihood for and concern about a COVID-19 diagnosis, suggesting that respondents were focused more on the severity of the disease than the perceived likelihood of contracting it. Less than one-half of the respondents viewed government websites (such as the CDC) as the most trusted source of COVID-19-related information. There was substantial distrust of information provided by the executive branch of government and concern about mixed messaging and information overload, highlighting the importance of consistent messaging from trusted sources that reaches all populations.

To read or post commentaries in response to this article, go to https://www. AnnFamMed.org/content/19/4/293/tab-e-letters.

Key words: novel coronavirus; COVID-19; messaging; communication; knowledge; perceptions; pandemic

Submitted May 6, 2020; submitted, revised, August 27, 2020; accepted October 29, 2020.

Author Affiliations: Department of Medicine, Pennsylvania State University, Hershey, Pennsylvania (L.J.V.S., B.S.); Department of Humanities, Pennsylvania State University, Hershey, Pennsylvania (L.J.V.S.); Department of Public Health Sciences, Pennsylvania State University, Hershey, Pennsylvania (L.J.V.S., E.W., V.M.C., A.E.Z., D.R.); Qualitative and Mixed Methods Core, Pennsylvania State University, Hershey, Pennsylvania (L.J.V.S., B.S., E.W.); Department of Family and Community Medicine, Pennsylvania State University, Hershey, Pennsylvania (E.L.M., A.E.Z., D.R., C.L.L., M.T.R., R.P.L.); Penn State College of Medicine, Pennsylvania State University, Hershey, Pennsylvania (D.L., O.T.); Penn State Law, Pennsylvania State University, University Park, Pennsylvania (R.P.L.); Department of Anesthesiology and Perioperative Medicine, Pennsylvania State University, Hershey, Pennsylvania (A.E.Z.).

Author contributions: Concept and design: L.J.VS, B.S., E.L.M., R.P.L., C.L.L., M.T.R., A.E.Z.; Acquisition, analysis, or interpretation of data: All authors; Drafting of the manuscript: L.J.VS., M.T.R., V.M.C., R.P.L.; Critical revision of the manuscript for important intellectual content: All authors; Statistical analysis: L.J.VS, M.T.R., V.M.C.; Obtained funding: L.J.VS., R.P.L., E.L.M., M.T.R., A.E.Z.; Administrative, technical or material support: B.S., E.L.M.; Supervision: L.J.VS., B.S., V.M.C, R.P.L.

Funding support: Research reported in this project was funded by the Huck Institutes of Life Sciences and the Social Science Research Institute of Pennsylvania State University, and the Department of Family and Community Medicine, Pennsylvania State College of Medicine. L.J.VS. has received funding from the National Institute of Health, Canadian Institute of Health Research, John and Wauna Harman Foundation, Society for Critical Care Medicine, the Francis Family Foundation, and Association for Clinical Pastoral Education. E.W. and B.S. receive funding from the Penn State Qualitative and Mixed Methods Core. R.P.L., D.R., and A.E.Z., and E.L.M. receive additional funding for other COVID-19 related studies from the Huck Institutes of Life Sciences and the Social Science Research Institute of Pennsylvania State University. Some authors may have additional funding sources unrelated to this study; this information is available upon request. The REDCap database used in this project was funded by The Penn State Clinical \& Translational Research Institute, Pennsylvania State University CTSA, NIH/NCATS Grant Number UL1 TR000127 and UL1 TR002014.

Role of the Funder/Sponsor: DFCM faculty were involved in study design and manuscript production. No other funders were involved in data collection, analysis, interpretation or any aspect of the manuscript production.

Acknowledgments: Without the assistance of the following individuals and groups, the scope and scale of this project would not have been possible. We thank Stacy Beers, Amy Peiffer and the Penn State Health and Penn State College of Medicine Marketing teams, Susan Chobanoff, Neal Thomas, Leslie Parent, Sarah Bronson, Heather Stuckey-Peyrot, and the Penn State Qualitative Mixed Methods Core. 
Supplemental materials: Available at https://www.AnnFamMed. org/lookup/suppl/doi:10.1370/afm.2674/-/DC1.

\section{References}

1. World Health Organization. Pandemic Influenza Preparedness and Response: A WHO Guidance Document. World Health Organization; 2009. https://www.who.int/influenza/resources/documents/ pandemic_guidance_04_2009/en/

2. Henrich N, Holmes B. Communicating during a pandemic: information the public wants about the disease and new vaccines and drugs. Health Promot Pract. 2011;12(4):610-619.

3. COVID-19: fighting panic with information. Lancet. 2020;395(10224): 537.

4. Hall K, Wolf M. Whose crisis? Pandemic flu, 'communication disasters' and the struggle for hegemony. Health (London). 2019: 1363459319886112.

5. Lin L, McCloud RF, Bigman CA, Viswanath K. Tuning in and catching on? Examining the relationship between pandemic communication and awareness and knowledge of MERS in the USA. J Public Health (Oxf). 2017;39(2):282-289.

6. Vaughan $E$, Tinker T. Effective health risk communication about pandemic influenza for vulnerable populations. Am J Public Health. 2009;99(Suppl 2):S324-S332.

7. Prati G, Pietrantoni L, Zani B. A social-cognitive model of pandemic influenza H1N1 risk perception and recommended behaviors in Italy. Risk Anal. 2011;31(4):645-656.

8. Asmundson GJG, Taylor S. Coronaphobia: fear and the 2019-nCoV outbreak. J Anxiety Disord. 2020;70:102196.

9. Sharma M, Yadav K, Yadav N, Ferdinand KC. Zika virus pandemicanalysis of Facebook as a social media health information platform. Am J Infect Control. 2017;45(3):301-302.

10. COVID-19 Dashoard by the Center for Systems Social Science and Engineering (CSSE) at Johns Hopkinds University (JHU). Accessed Apr 15, 2020. https://www.arcgis.com/apps/opsdashboard/index. html\#/bda7594740fd40299423467b48e9ecf6

11. Centers for Disease Control and Prevention. COVID-19 in racial and ethnic minority groups. Accessed May 2, 2020. Updated Jul 24, 2020. https://www.cdc.gov/coronavirus/2019-ncov/need-extraprecautions/racial-ethnic-minorities.html

12. Hamel LL, Muñana C, Kates J, Michaud J, Brodie M. KFF Coronavirus Poll: March 2020. Kaiser Foundation. Published Mar 17, 2020. https://www.kff.org/coronavirus-covid-19/poll-finding/ kff-coronavirus-poll-march-2020/
13. Creswell JW, Creswell JD. Research Design: Qualitative, Quantitative, and Mixed Methods Approaches. Sage Publications; 2017.

14. Municipal Public Health Service Rotterdam-Rijnmond (GGD), National Institute for Public Health and the Environment (RIVM). Effective Communication in Outbreak Management for Europe (ECOMEU). Standard questionnaire on risk perception of an infectious disease outbreak. Published Nov 2015. https://ecomeu.info/ wp-content/uploads/2015/11/Standard-questionnaire-risk-perceptionECOM-november-2015.pdf

15. Center for Disease Control and Prevention. Coronavirus (COVID-19), Accessed March 25, 2020. https://www.cdc.gov/coronavirus/2019ncov/index.html

16. Lenzner T, Neuert C, Otto W. GESIS survey guidelines; cognitive pretesting. GESIS - Leibniz Institute for the Social Sciences. Published 2016. 10.15465/gesis-sg_en_010. https://www.gesis. org/en/gesis-survey-guidelines/instruments/quality-of-survey-data/ cognitive-pretesting

17. Lavrakas P, ed. Encyclopedia of Survey Research Methods. Sage Research; 2008.

18. Palinkas LA, Horwitz SM, Green CA, Wisdom JP, Duan N, Hoagwood K. Purposeful sampling for qualitative data collection and analysis in mixed method implementation research. Adm Policy Ment Health. 2015;42(5):533-544.

19. Hsieh HF, Shannon SE. Three approaches to qualitative content analysis. Qual Health Res. 2005;15(9):1277-1288.

20. Glaser BG. The constant comparative method of qualitative analysis. Soc Probl. 1965;12(4):436-445.

21. Guetterman TC, Fetters MD, Creswell JW. Integrating quantitative and qualitative results in health science mixed methods research through joint displays. Ann Fam Med. 2015;13(6):554-561.

22. Wolf MS, Serper M, Opsasnick L, et al. Awareness, attitudes, and actions related to COVID-19 among adults with chronic conditions at the onset of the U.S. outbreak: a cross-sectional survey. Ann Intern Med. 2020;173(2):100-109.

23. Ye J. The role of health technology and informatics in a global public health emergency: practices and implications from the COVID-19 pandemic. JMIR Med Inform. 2020;8(7):e19866.

24. Dyer O. Covid-19: black people and other minorities are hardest hit in US. BMJ. 2020;369:m1483.

25. Yancy CW. COVID-19 and African Americans. JAMA. 2020;323(19): 1891-1892. 